\title{
Insulin secretion in human protein-calorie deficiency
}

\author{
By R. D. G. MrLner, Department of Child Health, University of Manchester, \\ Manchester 13
}

Insulin secretion in human protein-calorie deficiency has been studied in the last decade by groups of workers caring for children with different kinds of malnutrition in various parts of the world. Despite variation in the subjects, experimental design and laboratory methodology, there is general agreement that insulin secretion is reduced in malnourished man. The mechanism of the impairment of insulin release is complex and, for various reasons, has not been analysed in depth. In this communication, information on insulin secretion in malnutrition will be reviewed and the causes and consequences of the abnormality discussed.

\section{Experimental studies}

Most workers have made deductions regarding insulin secretion from changes in plasma concentrations of the hormone after the administration to malnourished infants of various substances known to cause insulin release in the normal adult. Interferences regarding insulin release made from intravenous glucose-tolerance tests in early studies have been confirmed subsequently by the direct measurement of plasma insulin concentrations. 'There is no report in the literature of the production rate or the half-life of insulin in malnutrition although work with other proteins has shown that both protein synthesis and catabolism may be reduced (Waterlow, r668). Polypeptide hormones, including insulin, may be similarly affected. The stimulus used most commonly for insulin release has been glucose given by mouth or intravenously, but more recently amino acids and glucagon have also been used to provoke insulin secretion. The infants studied have suffered from marasmus, marasmic kwashiorkor or kwashiorkor.

Bowie (1964) demonstrated that the disappearance rate $\left(k_{t}\right)$ of intravenously injected glucose in children with kwashiorkor was reduced and that the low $k_{t}$ was not influenced by intravenous infusions of $50 \mathrm{~g}$ glucose on each of $3 \mathrm{~d}$ prior to the test. Furthermore the subjects were insulin-resistant, having the same glucose tolerance in response to glucose as to glucose plus exogenous insulin. Later work (Baig \& Edozien, 1965; Hadden, 1967; Becker, Pimstone, Hansen \& Hendricks, I97I) confirmed the decreased glucose tolerance in kwashiorkor and demonstrated that plasma insulin concentrations both in the fasting state and after a glucose challenge were reduced. Analogous results were obtained with the use of oral glucose, but interpretation of the findings is difficult since gut atrophy occurs in protein- 

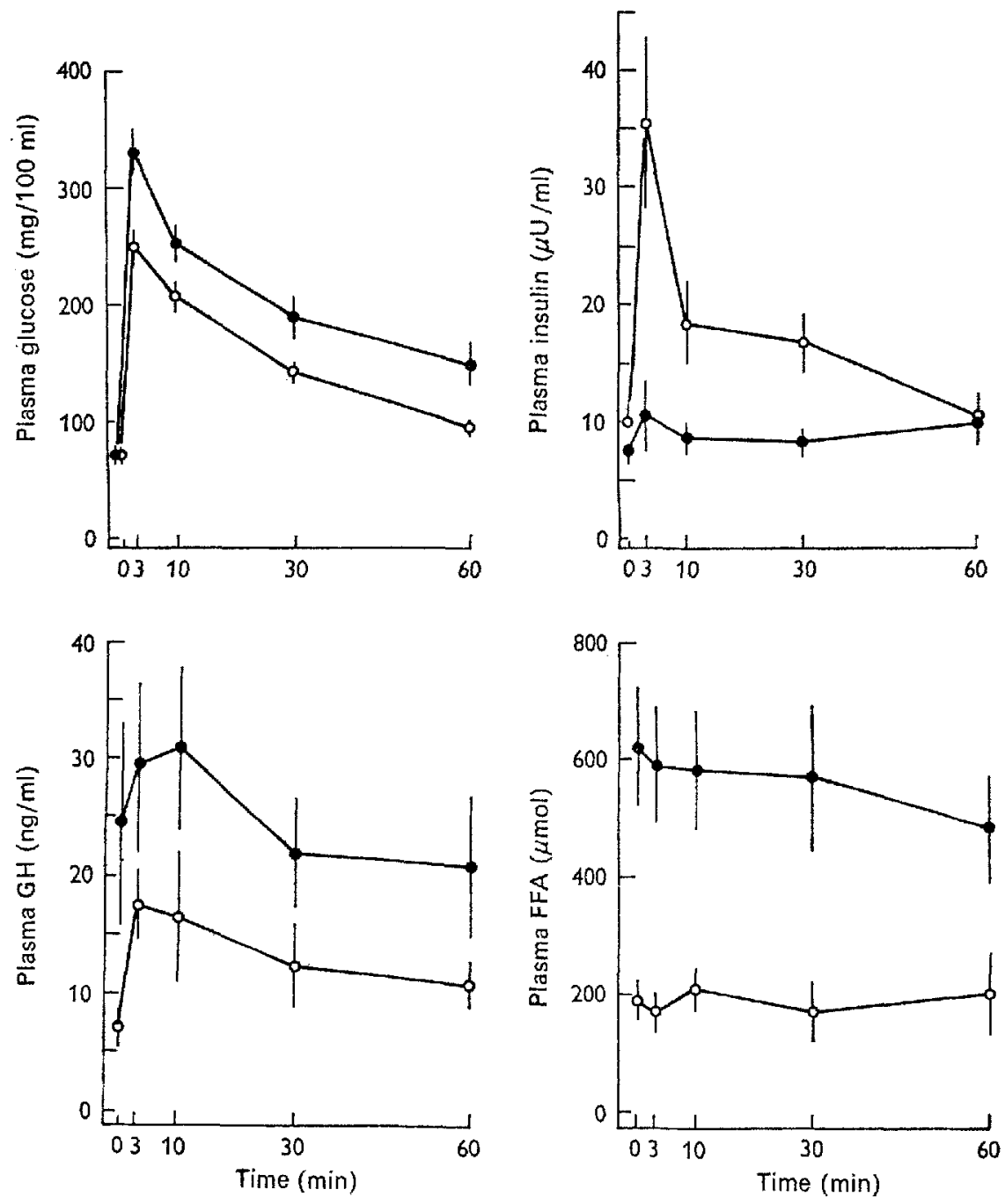

Fig. I. Concentrations of plasma glucose, free fatty acid (FFA), insulin and growth hormone (GH) in ten malnourished infants in response to intravenous glucose $(0.5 \mathrm{~g} / \mathrm{kg}$ body-weight). The vertical bars represent the standard errors of the mean. Measurements were made on the first or second day after admission (solid circles) and 6-12 weeks later (open circles). (Reproduced from Milner (1970), by permission of the Editor of Memoirs. Society for Endocrinology).

calorie malnutrition (Trowell, Davies \& Dean, 1954) and glucose absorption is known to be impaired (James, I968).

In marasmus, glucose tolerance is similar to that of control subjects (Bowie, 1964 ; Hadden, 1967; Godard \& Zahnd, 1971) despite low fasting plasma insulin concentrations and a poor insulin response to intravenous glucose. Hadden (1967) found a significant negative linear correlation between the glucose disappearance rate and the fasting plasma free fatty acid (FFA) concentration in kwashiorkor, but not in children with marasmus in whom FFA concentrations tended to be lower. 
He suggested that the high FFA concentrations were responsible, in part, for the poor glucose tolerance in kwashiorkor.

Infants with marasmic kwashiorkor responded to an intravenous glucose challenge like those with kwashiorkor (James \& Coore, x970; Becker et al. 1971; Milner, 1971a). By studying such children shortly after admission to hospital and again after clinical recovery it was possible to demonstrate that the poor glucose tolerance on admission was associated with no significant change in plasma insulin concentrations. Fasting plasma FFA and growth hormone (GH) concentrations were raised and did not fall, after the glucose injection (Fig. I). After clinical recovery some 6-12 weeks later, glucose tolerance improved. This was associated with normal FFA concentrations and a fall in fasting plasma GH concentrations. Plasma insulin concentrations rose $3 \mathrm{~min}$ after the glucose injection in the recovered children but fell thereafter despite the persistence of hyperglycaemia. In both ill and clinically recovered infants who had marasmic kwashiorkor it was not possible to induce a rise in plasma insulin concentrations using intravenous glucagon or a mixture of the ten essential amino acids given via a nasogastric tube (Milner, I97 $a, b$ ).

The evidence suggests that the return of $\beta$ cell function to normal occurs some months or years after clinical recovery. James \& Coore (I970) also found that Jamaican infants who had recovered clinically from marasmic kwashiorkor had poorer glucose tolerance and insulin secretion than normal, control subjects. The possibility of prolonged subnormal insulin sectetion is important in both the immediate growth of the child recovering from malnutrition and the pathogenesis of diabetes mellitus in communities where malnutrition is endemic. Normal $\beta$ cell function does not appear to be rate-limiting for satisfactory growth since the children studied in Jamaica grew at ten to fifteen times the normal rate during recovery despite poor insulin secretion ( $A$ shworth, I969). In an attempt to assess the longterm effects of malnutrition on $\beta$ cell function, Becker et al. (I $97 \mathrm{I}$ ) compared glucose tolerance and plasma insulin concentrations in ten children who had been hospitalized for protein-calorie malnutrition ro years previously, using as controls the nearest sibling in the family. No difference was seen between the two groups, but it must be noted that although the control siblings had not suffered overt malnutrition requiring hospitalization, they came from the same environment as the test subjects and might well have suffered some degree of chronic nutritional deprivation.

\section{Causes and consequences of abnormal insulin secretion}

The work cited above indicates clearly that both impaired insulin secretion and insulin resistance can occur in protein-calorie malnutrition. Other evidence of a more derivative kind must be adduced in the analysis of why insulin release is subnormal and the consequences of this.

The role of inorganic ions in the control of insulin secretion and action has received little attention in relation to human malnutrition. In particular, potassium and chromium may be of relevance. Infantile malnutrition is associated with a marked reduction of total body potassium (Garrow, 1965). Experimental studies 
in obese adults who fasted in order to lose weight (Anderson, Herman \& Newcomer, 1969) have shown that potassium deficiency per se is an important cause of impaired insulin release and glucose tolerance. An analogous specific effect of potassium deficiency in infantile malnutrition may be predicted. The effect of chromium on insulin secretion has not been studied direct but chromium chloride $\left(\mathrm{CrCl}_{3} \cdot 6 \mathrm{H}_{2} \mathrm{O}\right)$ has been shown to influence the glucose tolerance of some malnourished children. Carter, Kattab, Abd-El-Hadi, Davis, El Gholmy \& Patwardhan (1968) found no effect of chromium supplements on the impaired glucose tolerance of malnourished Egyptian children, whereas Hopkins, Ransome-Kuti \& Majaj (1968) found that a chromium supplement acutely improved the glucose tolerance of malnourished infants in Nigeria and Jordan. The Jordanian infants were all fed from a common source, but could be subdivided into two groups: those from hilly areas where the drinking-water contained 0.5 parts $/ \mathrm{I}^{12}$ chromium had impaired glucose tolerance which could be corrected in I6 h by $25^{\circ} \mu \mathrm{g}$ oral chromium chloride, whereas those from the valleys in which the drinking-water contained 1.5 parts $/ 10^{12}$ chromium had normal glucose tolerance. More recently, Gürson \& Saner (1971) demonstrated that marasmic Egyptian children could be subdivided into those with normal glucose tolerance and those with impaired tolerance. The glucose tolerance of the latter group could be improved promptly by $250 \mu \mathrm{g}$ chromium chloride orally. In both groups further improvement in glucose tolerance followed dietary treatment. Thus, two of three studies have clearly demonstrated a specific effect of chromium on the glucose tolerance of infants suffering from protein-calorie malnutrition. Whether the effect is manifested by altering insulin releasc, the action of circulating insulin or in some other way is unknown.

The pancreas is not spared from the atrophy of the gastro-intestinal tract which is seen in malnutrition. The histology and ultrastructure of the endocrine pancreas in human malnutrition has not been studied in detail, although the exocrine pancreas has been examined. The acini become disorganized with shrinkage of acinar cells which contain fewer zymogen granules, mitochondria and less endoplasmic reticulum than normal (Blackburn \& Vinijchaikal, 1969). Since endocrine pancreatic atrophy occurs in experimental malnutrition (Hcard \& Stewart, 1971) and exocrine pancreatic atrophy occurs in man, it seems most likely that insulin biosynthesis will be impaired in human protein-calorie malnutrition. It is possible that the release of gastro-intestinal factors such as 'gut-glucagon', known to affect the $\beta$-cell response to oral stimuli, will also be found to be impaired as a result of intestinal atrophy.

The effect of the hormonal imbalance produced by malnutrition on protein metabolism was studied by Graham, Cordano, Blizzard \& Cheek (1969). These workers found that malnourished Peruvian children had high plasma GH concentrations and low plasma insulin concentrations which were unresponsive to intravenous arginine. The muscle cells of the children were smaller than normal but not reduced in number (Cheek, Hill, Cordano \& Graham, I970). After clinical recovery the protein:DNA ratio of the muscle cells increased, but the cells remained smaller than normal. Cheek et al. (x970) speculated that the small cellular size after recovery was a consequence of persistent impairment of insulin secretion, and that cellular 
normality might be achieved in protein-calorie malnutrition if insulin were used therapeutically. The results presented were heterogeneous and insufficient to indicate clearly if low plasma insulin concentrations were associated with a delay in muscle growth. Even if insulin deficiency were demonstrated, the use of insulin therapeutically would be hazardous because of the variation in insulin resistance in different malnourished children.

The ability to measure insulin concentrations in small volumes of blood rapidly by immunoassay will encourage other workers to fill in the gaps in our knowledge concerning insulin secretion in malnutrition. However, it is not only to insulin but also to its companion hormone, glucagon, that we should now direct our attention in considering the endocrine pancreatic response to malnutrition. Recent advances in the physiology of glucagon secretion in the adult (Unger, $197 \mathrm{I}$ ) indicate that the hormone plays an important part in the metabolic adaptation to fasting and starvation (Cahill, I970), and is likely to be centrally involved, with insulin, in the hormonal response to protein-calorie malnutrition.

\section{REFERENCES}

Anderson, J. W., Herman, R. H. \& Newcomer, K. L. (1969). Am. F. clin. Nutr. 22, x 589.

Ashworth, A. (1969), Br. F. Nutr. 23, 835 .

Baig, H. A. \& Edozien, J. C. (1965). Lancet ii, 662.

Becker, D. J., Pimstone, B. L., Hansen, J. D. L. \& Hendricks, S. (I971). Diabetes 20, 542.

Blackburn, W. R. \& Vinijchaikal, K. (1969). Lab. Invest, 20, 305.

Bowie, M. D. (1964). S. Afr. med. F. 38, 328 .

Cahill Jr, G. F. (เ970). New Engl. $尹$. Med. 282, 668.

Carter, J. P., Kattab, A., Abd-El-Hadi, K., Davis, J. T., El Gholmy, A. \& Patwardhan, V. N. (I968). Am. Y. clin. Nutr. 21, 195.

Cheek, D. B., Hill, D. E., Cordano, A. \& Graham, G. G. (1970). Pediat. Res. 4, 135.

Garrow, J. S. (1965). W. Indian med. F. 14, 73 .

Godard, C. \& Zahnd, G. R. (I97I). Helv, paediat. Acta 26, 276.

Graham, G. G., Cordano, A., Blizzard, R. M. \& Cheek, D. B. (1969). Pediat. Res. 3, 579.

Gürson, C. T. \& Saner, G. (197r). Am. J. clin. Nutr. 24, r313.

Hadden, D. R. (1967). Lancet ii, 589 .

Heard, C. R. C. \& Stewart, R, J. C. (1971). Hormones 2, 40.

Hopkins, L. L. Jr, Ransome-Kuti, O. \& Majaj, A. S. (1968). Am. F. clin. Nutr. 21, 203.

James, W. P. T. (I968). Lancet i, 333 .

James, W. P. T. \& Coore, H. G. (1970). Am. Y. clin. Nutr. 23, 386.

Milner, R. D. G. (1970). Mem. Soc. Endocr. 18, 191.

Milner, R. D. G. (1971a). Pediat. Res. 5, 33.

Milner, R. D. G. (г97 г)). Archs Dis. Childh. 46, 30г.

Trowell, H. C., Davies, J. N. P. \& Dean, R. F. A. (editors) (1954). Krvashiorkor p. 308. London: Edward Arnold.

Unger, R. H. (1971). New Engl. F. Med. 285, 443.

Waterlow, J. C. (1968). Lancet ii, I091. 